\title{
A SEMI-AUTOMATED POINT CLOUD PROCESSING METHODOLOGY FOR 3D CULTURAL HERITAGE DOCUMENTATION
}

\author{
C. Ö. Kıv1lcım*, Z. Duran \\ ITU, Civil Engineering Faculty, Dept. of Geomatics Engineering Maslak Istanbul, Turkey - kivilcim, duranza@itu.edu.tr
}

\author{
Commission VI, WG VI/4
}

KEY WORDS: Cultural Heritage Documentation, Laser Scanning, Point Clouds, Algorithms, Open Source Programming, BIM

\begin{abstract}
:
The preliminary phase in any architectural heritage project is to obtain metric measurements and documentation of the building and its individual elements. On the other hand, conventional measurement techniques require tremendous resources and lengthy project completion times for architectural surveys and 3D model production. Over the past two decades, the widespread use of laser scanning and digital photogrammetry have significantly altered the heritage documentation process. Furthermore, advances in these technologies have enabled robust data collection and reduced user workload for generating various levels of products, from single buildings to expansive cityscapes. More recently, the use of procedural modelling methods and BIM relevant applications for historic building documentation purposes has become an active area of research, however fully automated systems in cultural heritage documentation still remains open. In this paper, we present a semi-automated methodology, for 3D façade modelling of cultural heritage assets based on parametric and procedural modelling techniques and using airborne and terrestrial laser scanning data. We present the contribution of our methodology, which we implemented in an open source software environment using the example project of a 16th century early classical era Ottoman structure, Sinan the Architect's Şehzade Mosque in Istanbul, Turkey.
\end{abstract}

\section{INTRODUCTION}

Cultural heritage structures play an important role in sustaining the relationship between man and his past. In order to preserve cultural heritage assets for the next generations, fast and accurate documentation of structures and their surrounding areas based on scientific techniques need to be developed. Laser scanning technology has become widely used over the last decade for conservation and documentation projects. Further, systems that integrate point cloud processing methodologies with Building Information Modeling (BIM) applications for efficient final products for preserving and managing cultural heritage structures are gaining importance. In this paper we present a methodology for decreasing the user input in the geometry generation of architectural elements with a special emphasis to classical era Ottoman mosque design elements.

\subsection{Cultural Heritage Documentation from Point Clouds}

Over the past decade, the use of laser scanning and digital photogrammetry to document cultural heritage structures has come into popular use. Georeferenced data acquisition is conducted by geomatics experts, while architects and conservation experts have the responsibility of interpreting the derived point clouds into architectural drawings for documentation projects. Yet, from point clouds to 3D modelling, the digitalization pipeline is still based primarily on manual measurements and processing.

Architectural survey production from point clouds is a complex process and depends mostly on human interpretation. Therefore, technicians need to understand the data to describe the surfaces on the point cloud carefully for any final output. This process is time consuming and requires expertise in data manipulation. Difficulties understanding the point cloud environment and inconsistencies in the $3 \mathrm{D}$ environment, such as picking points from various surfaces, increase editing and processing times. There is an active interest in research community from geomatics and computer vision domains to increase the automation for various aims; such as city modelling to robotics. 3D façade documentation is a subtopic of the 3D city/building modeling. The demand for 3D city models motivated Gruen and Hendriccson (1997) to develop two projects in order to generate semi and fully automated 3D building models based primarily on aerial imagery. The module TOBAGO (Dan, 1996, Gruen, Dan, 1997), a semi-automatic approach where a generic roof models library was used to construct 3D detailed roofs and extrude them to 3D building models. The sister project ARUBA (Henricsson, 1996, Henricsson et al., 1996), an approach for a fully automated detection/reconstruction process, aims to detect and reconstruct the building itself. Henricsson (1996) also projected façade textures from photographs to increase the $3 \mathrm{D}$ data view for a realistic visualization to $3 \mathrm{D}$ roof extractions are accomplished in authors' experimental work (Gruen and Henricsson 1996).

Gruen (2000) demonstrates that the fully automated applications based on image processing are only successful in highly structured images, like those found in industrial applications, therefore for other situations, like complex architectural heritage structures, semi-automated procedures are necessary. Gruen also recommends that additional sensor information, such as Lidar point clouds and GIS data related to the objects, be used as secondary data sources.

With advances in scanner speed, higher point densities and accuracies, and increased computational capacities, laser scanners became a favourable technique for structure documentation. However, there is still much work to be done to move from unstructured point clouds to full automation in modelling. The commercial products highly depend on manual 
editing of point clouds and digitization based on technical expertise and skills.

For more than a decade research has been ongoing for automated modelling methodologies, to name a few, yet there is no single fully capable system yet.

\subsection{Relevant Work for Geometric Modelling and BIM from Point Clouds}

De Luca, Veron, \& Florenzano (2006) present an approach that combines point cloud and image based modeling techniques, and integrates it with architectural feature-based modeling. They first produced the library of relevant architectural element profiles and produce semantic representations of architectural elements and organize them into hierarchical structures. They introduce a three step method according to the morphological complexity of classical period architectural elements. Architectural elements are chosen and adjusted to basic primitive units then a parametric description is applied with a set of low level primitives from relevant architectural profiles. A library of parameterized architectural primitives is instantiated onto the point cloud in a manual frame. This hybrid methodology is based on the construction of the building model from metric survey and photographic data. The last phase of the workflow focuses on semantic organization and configuration of the 3D model in order to allow an efficient handling of the resulting digital mock-up.

A semantic approach to automatically recover building façades from terrestrial laser scanning point clouds is presented by $\mathrm{Pu}$ and Vosselman (2009). To obtain potential building features they first segment the point cloud into planar elements. Later, extracted parts are categorized into semantic elements such as walls, doors and windows segments using generic building knowledge and characteristics such as size, position, orientation and topology. They also use semantic knowledge to produce the occluded parts. Polyhedral building façade model is produced by the fitting and merging of the extracted polygons and their final product contains semantic labels that can be associated with object based geo-databases. Hichri, Stefani, Luca, \& Veron (2013) underline the semantically enriched digital models can benefit from the Building Information Modelling. They propose an approach to link the data acquisition and the final "as-built" BIM.

Dore \& Murphy (2014) use a strategy to provide easy access and overcome the limitations of point clouds for further usage within conservation activities. They use parametric and procedural modelling techniques based on architectural knowledge and call their design as "Heritage Building Information Modeling." The system contains an interactive library of parametric architectural objects that have been designed from architectural drawings of classical era. They create scripts of objects, embed them into a commercial software archiCAD BIM and map the objects on laser point clouds and image based survey.

A more recent work has been carried by Thomson \& Boehm (2015). Their work focuses on the Automatic Geometry Generation of building interior from point clouds. Following the commercial standards, they present a methodology that uses RANSAC algorithm to wall segmentation and with spatially reasoning they reject, extend or merge the planes.

As seen in the presented works, the trend for cultural heritage documentation with point clouds has moved from digital reconstructions towards complete BIM systems for existing structures.

\section{ARCHITECT SINAN, HIS MONUMENTS AND ŞEHZADE MOSQUE}

Mimar Sinan (1489-1588), chief of architects and engineers of the Ottoman Empire for nearly half a century, designed, located and constructed over 400 innovative structures. Sinan's service during the reign of Sultan Süleyman the Magnificent, he designed and constructed a number of mosques for royal family members, important soldiers and high level state authorities, and for sultan himself, as well as numerous constructions throughout the Empire. Sinan himself described Şehzade Mosque as his apprenticeship milestone in his career Figure 1 (Kuran, 1986; Kuban, 2007).

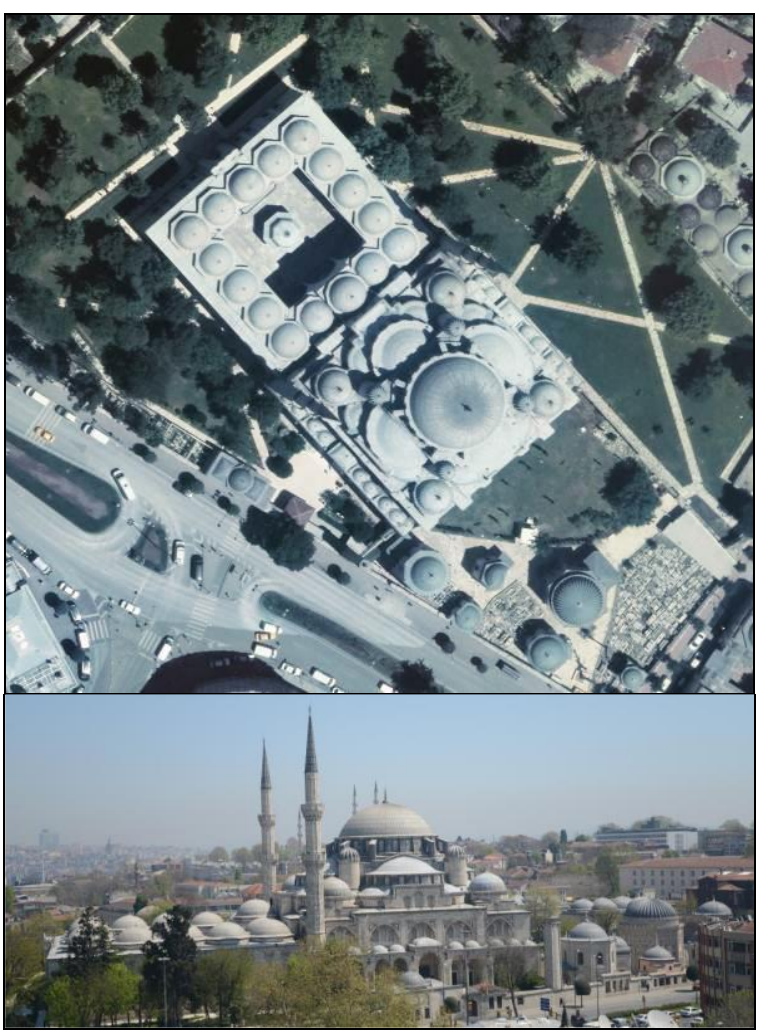

Figure 1. Şehzade Mosque in aerial imagery on top and SW direction façade view.

Sinan's Şehzade Mosque in Istanbul played an important role in defining the Ottoman Empire classical mosque design which was also adapted by Sinan's successors to produce famous mosques such as Sultan Ahmet Mosque (1616) and Yeni Cami (1665), as well as many others throughout the Ottoman Empire, and continues to serve as a cornerstone of mosque design in the Turkish Republic today. In this sense, using Şehzade Mosque as an example to produce a library of parametric architectural elements would mean to serve as a basis for documentation and design of existing and future mosques. 


\subsection{Datasets}

In our study we used point cloud datasets derived from airborne and terrestrial laser scans by Bimtas, produced for Istanbul Metropolitan Area Digital 3D City Model project.

The data collection for this project began in 2013 and it contains airborne Lidar and terrestrial laser scans of Şehzade mosque as well as a number of additional historic sites Figure 2.

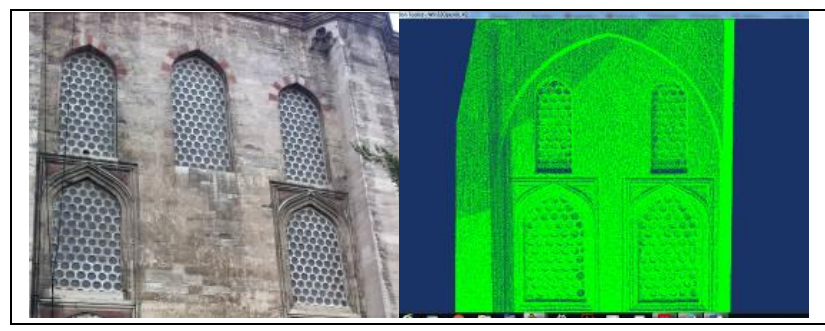

Figure 2. A part exemplary façade with different window design elements seen in the image and relevant point cloud.

A Riegl VZ-400 series scanner was used to collect a terrestrial scan of the Şehzade Mosque Complex using 150 scan stations. Riegl Q680i was used for airborne project with a point density more than $16 \mathrm{pt} / \mathrm{m}^{2}$, while terrestrial scans easily achieve $\mathrm{cm}$ level point distance at average on different facades of Şehzade Mosque. Data collection was intended to acquire every object in detail, the mosque and surrounding areas were captured, resulting in a very dense point cloud that could be used in a variety of applications. We used a selected area of the data available for testing our first application on project to complete modelling of the mosque complex.

\subsection{Open Source Programming}

Python language was chosen for its rapid prototype development skills and easy to code user friendliness syntax as well as its wide use. Python is open source object oriented high level and platform independent programming language. It includes many powerful modules and packages, an advanced multi-dimensional array and matrices, and high level mathematical functions, such as numpy. In addition, many third-party applications have integrations with Python. For our purpose we use Python wrappings of Visualization Tool Kit Library (VTK). VTK is a very efficient and integrated library based on Open Graphics Library. It is as an open source software system for 3D computer graphics image processing and visualization based on $\mathrm{C}++$ and coming with python interpreted interface layers and a python implementation. VTK supports a wide variety of scientific visualization algorithms and advanced modelling techniques and can be integrated with various databases on GUI toolkits. Our implementations are based on open source modules and classes which are also publicly available in various platforms.

\subsection{Data About Architectural Design}

Although there is a vast literature on how Sinan developed the mosque design structurally, there is little reserach done on Sinan's architectural design of the façade plans. Known architectural façade plans from historic architectural documentations such has the hand drawn surveys from Arch. Ali Saim Ülgen were used at planning phase seen in Figure 3.

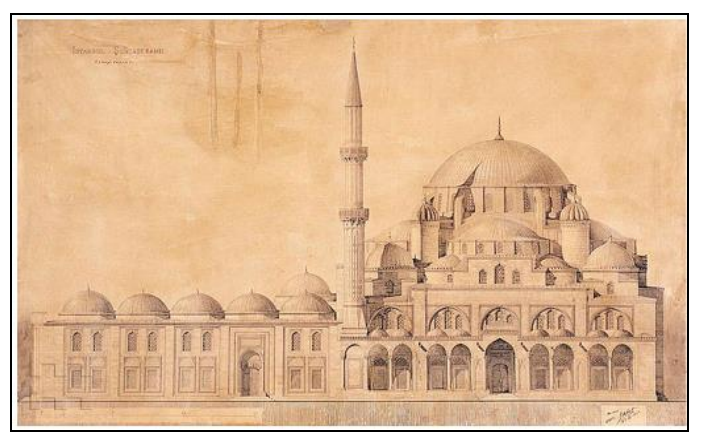

Figure 3. An example of old architectural survey of Şehzade Mosque hand drawn by Arch. Ali Saim Ülgen from early 1960s.

\section{METHODOLOGY}

Our methodology seeks solutions for existing difficulties based on the heavy manual workload on architectural survey production process from laser point clouds. It is based on the extracting geometry of the architectural elements from the point cloud requiring less user input and more control over extracting the façade element details. For this, we used open source programming language and classes for computing and visualizing with VTK.

At this first stage of our work on geometry generation, we began by implementing our methodology to be used in window geometries of mosque façades. Parametric architectural library elements were defined based on the available information on architect Sinan's works with a special emphasis on the Şehzade Mosque (Figure 4). To define the parametric architectural façade elements and their configurations in library we used work of Erzen J. N. (1981) that describes Architect Sinan's design patterns primarily on his mosque facade designs.

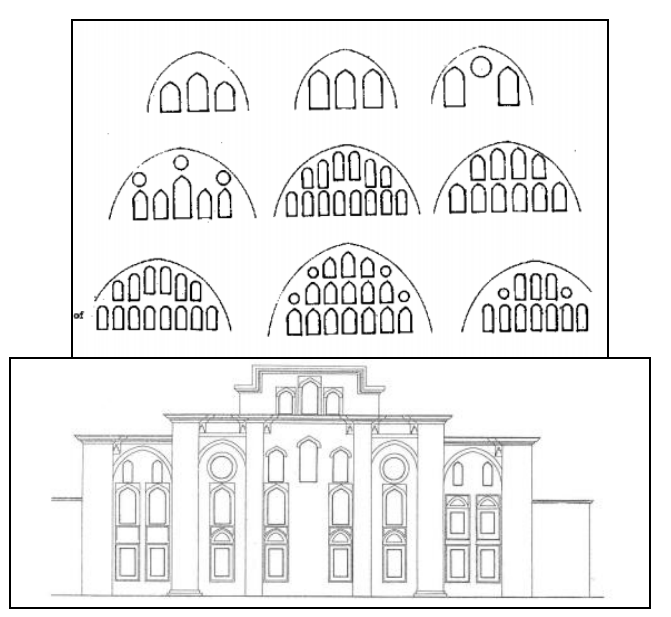

Figure 4. Window groupings within the shape of arch in Sinan's mosques and South East façade plans layout of Şehzade (Erzen J. N., 1981).

In developed application, user selects the area of interest (the window in this case), in the point cloud area, and selects the window type from the library (Figure 5), we compute point normals and cluster the point data, and run RANSAC algorithm to detect the planes, cylinders and spheres in the given point cloud. 


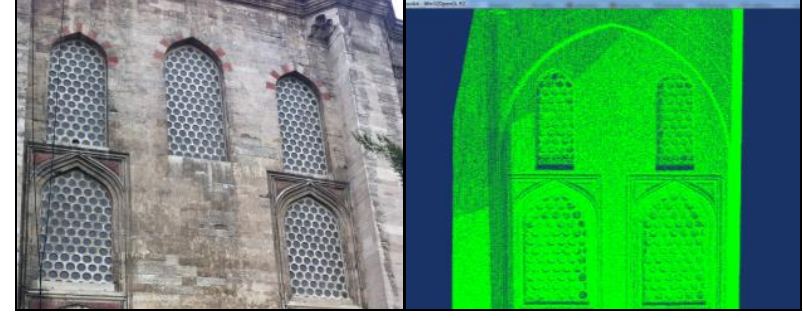

Figure 5. A sample of façade element with different window design elements seen in the image and relevant point cloud.

RANSAC algorithm introduced by Fischler \& Bolles (1981) is an efficient algorithm that is widely used in computer vision for detecting simple shapes both in $2 \mathrm{D}$ and $3 \mathrm{D}$ point clouds. With the output we determined approximate shapes that are parts of the window features. Following this, the user can match relevant points to match the selected library elements (Figure 6 and Figure 7 )

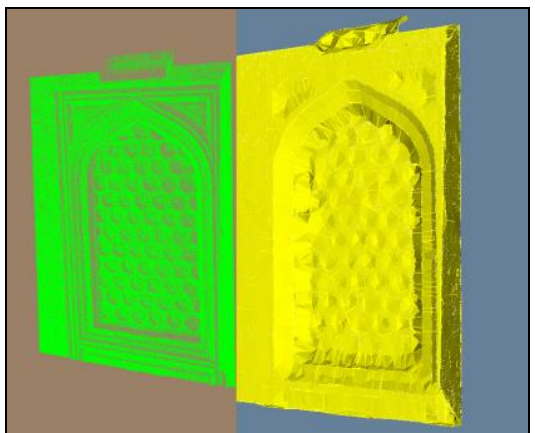

Figure 6. Detailed point cloud view of a window and its generated simplified triangulated surface as a intermediate.

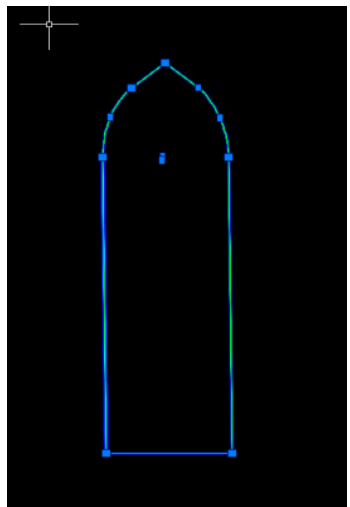

Figure 7. An example of window drawing with vertices, which is used to determine the window parameters.

\section{CONCLUSIONS AND FUTURE WORKS}

Şehzade Mosque is accepted as a key for the classical mosque design in Turkey and has been copied in historic and numerous new mosques. However, the façade plan design has been little researched. According to the first findings using the methodology presented here, we plan to extend the current window library to the different architectural elements of the mosque. The system will propose the window type according to the algorithm results and increase the automation in digital modelling. In addition, developing a semantic database and converting the final product to BIM industry standards will be focused on long term implementation for architectural documentation, survey and management of historic mosques.

\section{REFERENCES}

Dan, H., 1996. Rekonstruktion generischer Gebäudemodelle aus Punktwolken und deren Abbildungskorrekturen in Orthobildern. Ph.D. Thesis, Swiss Federal Institute of Technology (ETH) Zürich, Diss. ETH Nr. 1175, Published in Mitteilungen Nr. 60 of the Institute of Geodesy and Photogrammetry.

De Luca, L., Veron, P., \& Florenzano, M. (2006). Reverse engineering of architectural buildings based on a hybrid modeling approach. Computers \& Graphics, 30(2), 160-176.

Dore, C., \& Murphy, M. (2014). Semi-Automatic Generation Of As- Built Bim Façade Geometry From Laser And Image Data, 19 (January), 20-46.

Fischler, M. a, \& Bolles, R. C. (1981). Random Sample Consensus: A Paradigm for Model Fitting with Applicatlons to Image Analysis and Automated Cartography. Communications of the ACM, 24(6), $381-395$.

Gruen, A., Dan, H., 1997. TOBAGO - a topology builder for the automated generation of building models. Proceedings of the Monte Verità Workshop "Automatic extraction of manmade objects from aerial and space images" (II), (eds.: Gruen, Baltsavias, Henricsson), Birkhäuser Verlag, Basel, Switzerland, Monte Vérita, 4-9 May, pp. 149-160.

Henricsson, O., 1996. Analysis of image structures using color attributes and similarity relations. Ph.D. Thesis, Swiss Federal Institute of Technology (ETH) Zürich, Diss. ETH, Nr. 11663, Published in Mitteilungen Nr. 59 of the Institute of Geodesy and Photogrammetry.

Henricsson, O., Bignone, F., Willuhn, W., Ade, F., Kübler,O., Baltsavias, E., Mason, S., Grün, A., 1996. Project AMOBE: Strategies, current status and future work. IAPRS, Vol.31, Part B3, pp. 321-330.

Hichri, N., Stefani, C., Luca, L. De, \& Veron, P. (2013). Review of the «As-Built Bim» Approaches. 3D-ARCH 2013 3D Virtual Reconstruction and Visualization of Complex Architectures, XL-5/W1(February), 107-112.

Kuban, D., 2007. Osmanlı Mimarisi. Yapı Endüstri Yayınları, İstanbul pp. 17-20.

Kuran, A., 1986. Mimar Sinan, Hürriyet Vakfı Yayınları, İstanbul pp. 22-23.

Thomson C, Boehm J., 2015. Automatic Geometry Generation from Point Clouds for BIM. Remote Sensing.7(9) pp. 1175311775. 